\title{
Potenciación de la condición humana: tarea de las humanidades en la educación superior
}

\author{
Strengthening the human condition: \\ The task of the humanities in higher education
}

Potencializando a condição humana: a tarefa das humanidades na educação superior, Alexandra Astudillo Figueroa

\author{
Alexandra Astudillo Figueroa \\ Universidad San Francisco de Quito \\ E-mail: aastudillo@usfq.edu.ec
}

\section{Resumen}

Si revisamos la historia de la educación, podemos constatar que las propuestas pedagógicas surgieron en la medida que las sociedades evolucionaban y demandaban más respuestas desde la educación para la formación y acción de sus ciudadanos. Actualmente, observamos con preocupación discursos y prácticas orientados a desplazar a las humanidades de la propuesta curricular universitaria. Fundamentados en argumentos como la poca empleabilidad de sus graduados y la necesidad de dar respuesta a las exigencias de un mercado laboral cada vez más competitivo, se debate sobre la real utilidad de las humanidades y se presiona para eliminar la formación humanística de los claustros universitarios. Este artículo postula que, precisamente dadas las condiciones del mundo actual, es primordial la formación en las humanidades, ya que es urgente restaurar a una sociedad indiferente, autorreferencial, superficial e inmediatista por medio de futuros profesionales auténticos y responsables, con aptitud y actitud, competitivos y formados, con una elevada conciencia colectiva y humana. 
Palabras clave: Educación superior, humanidades, condición humana, persona, educación extática.

\section{Abstract}

If one reviews the history of education, it can be established that pedagogical propositions emerge from the evolutionary process of societies which demand more educational solutions for the training and actioning of citizens. Currently, there are concerning discourses and practices that attempt to displace the humanities from the university's curricular offer. Based on arguments such as the low employability of students after college and the need to answer to the demands of a labor market that is ever more competitive, these debates focus on the humanities' actual usefulness and they push for the elimination of a humanistic training from college campuses. This article proposes that, on the contrary, given the current state of affairs, a training in the humanities is essential because this indifferent, self-referential, superficial, and unmediated society can only be restored through genuine and responsible professional futures that are competitive and informed, with attitude and ability, and that can foster a collective human elevated consciousness.

Key words: Higher Education, humanities, human condition, personhood, ecstatic education.

\section{Resumo}

Revisando a história da educação, podemos constatar que as propostas pedagógicas surgiram à medida que as sociedades evoluíam e, assim, demandavam mais respostas da educação para a formação e ação dasos cidadãs-ãos. Atualmente, observamos com preocupação discursos e práticas que têm como objetivo a eliminação das humanidades dos currículos universitários. Fundamentados em argumentos como a baixa empregabilidade das-os graduandas-os e a necessidade de dar respostas 
às exigências de um mercado de trabalho cada vez mais competitivo, debate-se a utilidade real das humanidades e se pressiona para a exclusão da formação humanística dos programas universitários. Este artigo postula que, dada as condições do mundo atual, a formação em humanidades é primordial, uma vez que é urgente restaurar a uma sociedade indiferente, auto-referencial, superficial e imediatista, por meio de futuros profissionais autênticas-os e responsáveis, com aptidões e atitudes, competitivas-os e formadas-os com uma elevada consciência coletiva e humana.

Palavras-chave: Educação superior, humanidades, condição humana, pessoa, educação extática.

\section{Introducción}

Terencio en su comedia Heauton Timoroumenos ${ }^{1}$, del año 165 a.C., pone en boca del personaje Cremes la siguiente frase "Homo sum, humani nihil a me alienum puto"2 (Jocelyn, 2015. p. 14). Esta frase que resuena desde hace más de 2000 años encarna la centralidad de la condición humana: una naturaleza comprometida con su entorno y su historia, que se proyecta de lo particular a lo universal, abierta a lo finito y a lo infinito, esencia que no puede ser traicionada. Si recorremos la historia de la universidad como institución educativa desde sus inicios hasta su consolidación en el siglo XIX, podemos ver que las humanidades han sido el eje de su configuración. No es casualidad que en la universidad alemana la filosofía haya tenido un papel central y, en la norteamericana, la formación literaria (Díaz Villarreal, 2015, p. 32).

1 El enemigo de sí mismo

2 "Hombre soy, nada de lo humano me es ajeno". 
Qué está pasando en el siglo XXI para que en mayor o menor grado se vaya difundiendo la idea de que hay una crisis de las humanidades (Mollis, 2003; Cots Vicente, 2006; Guerra, 2008; Cordua, 2012; Cifuentes Medina, 2014), de que estas ya no tienen lugar en la universidad, por medio de argumentos que van desde los bajos niveles de empleabilidad de sus graduados hasta la desvalorización de su función en la formación de los futuros profesionales. El objetivo de estas reflexiones es el de proponer no solamente que las humanidades son imprescindibles en la formación de un ser humano (Bullock, 1989; Ibáñez-Marín 1995; Culler, 1998; Blecua 1999; Nussbaum, 2005), sino que, fundamentalmente, ellas pueden ser uno de los medios para elevar la condición humana de las personas hoy devenidas en espectadores pasivos de la realidad que los circunda, instrumentalizados por decisiones mercantilistas, convertidos en consumidores irreflexivos, sumergidos en un ámbito tecnológicamente arrollador.

Estas reflexiones se sustentan en una revisión tanto de algunas propuestas que concentran los argumentos que restan relevancia a las humanidades como parte de la formación universitaria, como de aquellas que contribuyen con los principales argumentos para sustentar su vigencia. Una vez analizadas las distintas proposiciones he podido constatar que, tanto unas como otras, fundamentan su argumentación más en la utilidad de las humanidades, en el carácter práctico de su inclusión, que en su razón de ser. Esta constatación me ha llevado a las siguientes preguntas: ¿qué hay en el ser humano para que a lo largo de la historia haya impulsado el desarrollo de las humanidades?, ¿por qué el ser humano de distintos tiempos y culturas ha buscado en ellas la posibilidad de trascender? Para responder a estos interrogantes he indagado en la propuesta de una 'Pedagogía del éxtasis' que desarrolla Fernando Rielo Pardal, para entender la razón intrínseca a la condición humana que justifica la permanencia de las humanidades en las aulas universitarias. 


\section{La degradación de la condición humana}

Actualmente, parece que se olvida que las personas son las protagonistas de la historia y no el dinero, la técnica y el mercado. Las imágenes y cobertura mediática de individuos que consiguen fama, dinero, y poder, y sus excesos se han convertido en los modelos que se promueven y difunden. El bombardeo de esta manera de concebir el éxito está llevando a vaciar de sentido el horizonte humano y de ser humano: un individuo hecho para hacer cosas y no para ser persona, para producir y no para preguntar, para consumir y no para contemplar, para simular y no para ser.

Alrededor del mundo hay masas moviéndose en una u otra dirección sin fundamentos sólidos de cohesión, que necesitan de una mayor reflexión crítica sobre el objetivo que les mueve, sobre el punto de llegada de la ruta por donde se desplazan o la construcción de una interrelación sólida entre quienes caminan en una misma dirección. La superficialidad y rapidez con que se congregan y separan parecería decirnos que se está perdiendo el sentido colectivo de la existencia, hay una suerte de individualidades identitarias ligeras y mutantes, huérfanas de interiorización, de dirección, e inclusive de sentido.

Esta celebración del individualismo es producto de la inserción en una lógica perversa que encierra a la persona en sí misma, que distorsiona su visión, que la encarcela en una suerte de egolatría miope, que le niega la posibilidad de definirse como un ser en relación, de abrirse a los demás, de promover la acogida y el encuentro. Este debilitamiento de la condición humana incide en la manera de concebir el hecho pedagógico, orientado más hacia difundir información que generar experiencias formativas, a desarrollar aptitudes sin que cambien las actitudes de quienes se educan.

Este vaciamiento de la concepción de ser humano tiene como aliado a un vertiginoso desarrollo tecnológico, que ha desbordado todos los límites de la imaginación y el entendimiento, y ha cambiado dramáticamente la manera de concebir el conocimiento y el acceso a la información. Nunca antes ha estado como ahora, a la distancia de un clic, obras maestras de todos los tiempos, 
bibliotecas, bases de datos, archivos históricos, pictográficos, musicales, imágenes, gráficos, textos, pero también, pocas veces como ahora, el conocimiento se ha convertido en sinónimo de dominio de información y no en sabiduría, y el acto pedagógico, en un evento de consumo que cada vez se aleja más de ser una experiencia comunicativa generada por una interacción que, dada la particularidad de cada persona, es única e irrepetible.

Junto a este vaciamiento de lo que es ser humano, también hay un vaciamiento de la idea de cultura que lleva a un vaciamiento del objeto de las humanidades (Díaz Villarreal, 2015, p. 32). Como señala Díaz Villarreal, "ahora lo único evidente es que nada es evidente en el ámbito de la cultura: ni el valor, ni la calidad estética, ni la prioridad de algunos objetos simbólicos sobre otros. En las condiciones actuales, todo es susceptible de convertirse en cultura y, por lo tanto, cualquier cosa puede devenir objeto de las nuevas humanidades" (2015, p. 33). En un mundo regido por el imperio del mercado y tan globalmente conectado hay un desplazamiento de las nociones de cultura y una nueva regulación valorativa; es más importante la imagen que el contenido, es más mediático el ruido que lo que comunica, se privilegia la descripción sobre el análisis, y la celebración de la novedad sobre la trascendencia.

La jerarquización que debe caracterizar toda apropiación cultural es vista inmediatamente como elitismo reaccionario, como incapacidad para aceptar el valor de "lo otro"; y las nuevas humanidades en la era de la economía del conocimiento transforman los bienes culturales en reflejos de valores excluyentes o excluidos, según sea el caso: lo clásico, lo canónico, encarnan valores elitistas y antidemocráticos, mientras que lo marginal, lo poco valorado, son la cristalización de identidades excluidas por un sistema antidemocrático. De ese modo, el discurso económico y el discurso académico terminan por coincidir, sin que este último parezca notar que la desmitificación a la que cree someter los bienes culturales ya había sido llevada a cabo con más eficacia por las políticas económicas y las presiones del mercado (Díaz Villarreal, 2015, p. 33). 
Parecería que las humanidades "ya no tienen mucho que aportar en la economía globalizada del conocimiento, a excepción de algunas nociones fragmentarias dirigidas al incremento de la producción" (Díaz Villarreal, 2015, p. 32). Inclusive, "los planes de enseñanza en general tienden a reforzar los conocimientos científicos o técnicos a los que se supone una utilidad práctica inmediata, es decir una directa aplicación laboral" (Savater, 1997, p. 113), en detrimento de los conocimientos humanísticos y experienciales.

Esta desvalorización de las humanidades, orquestada desde una lógica de mercado que sigue el ritmo de la globalización, ha ingresado con fuerza en las decisiones que los estados toman respecto al tipo de universidades que quieren financiar, decisiones que van desde la aprobación de los programas académicos y carreras hasta la disponibilidad de recursos para investigación, desde la fijación de la excelencia sin más, como fundamento del perfil de graduados hasta la infraestructura que debe coadyuvar a dicho perfil, todo ello sustentado en un cuerpo docente que debe combinar su ejercicio pedagógico con investigaciones y publicaciones sometidas a estrictos controles y estándares internacionales, en una carrera desenfrenada por producir; de esta manera, tanto estudiantes como profesores están insertos en una competencia despiadada para alcanzar ciertos parámetros de excelencia, que se mueven según la lógica del mercado.

En este contexto, el conocimiento se convierte en algo descartable o en una herramienta meramente funcional que se la usa según la necesidad más inmediata, externa a la naturaleza de quien conoce y distante también de su transformación y crecimiento personal. En medio de este panorama, cada vez va quedando rezagada o ignorada la persona que enseña y la persona que se educa. Desdibujados detrás de las cifras, estándares, percentiles, hay seres humanos que no tienen espacio ni tiempo para la cultura, para la reflexión, para la contemplación, para descubrirse a sí mismas, personas que ahogan las preguntas trascendentales de su existencia en un ritmo desenfrenado por producir, sin espacio para la 
reflexión sobre la relación que tiene lo que produce con su origen y su fin último.

\section{Una pedagogía para la potenciación de la condición humana}

Este ritmo vertiginoso hacia la deshumanización requiere hoy, más que nunca, de propuestas que reflexionen sobre las acciones que pueden generarse en todos los contextos educativos, desde la familia hasta las instituciones académicas para ir recuperando una auténtica humanización en el ejercicio educativo. El mundo descentrado, escindido y caótico necesita urgentemente experiencias educativas que permitan encontrar unidad, dirección y sentido a la existencia, que vigoricen la condición humana, por naturaleza abierta a la trascendencia, a la generosidad, la entrega, la confianza, la buena voluntad, la belleza, el sentido de la verdad, de la justicia, valores que han sido enarbolados por las juventudes de todas las épocas y culturas.

¿Cómo recuperar o no perder esta condición que nos define? Para lograr esta apertura, hay que considerar que "la esencia del acto educativo no se encuentra en los enfoques didácticos ni en metodologías de enseñanzaaprendizaje, aunque éstos sean enormemente convenientes en el proceso educativo" (López, 1985, p. 12). Lo primordial es educar, como señala el filósofo y poeta español Fernando Rielo, "la fuerza extática del espíritu humano, pues ésta es la que proporciona al docente y al discente la motivación necesaria para cualquier enseñanza y aprendizaje" (2001a, 111). Esta permite tanto al profesor como al discípulo tomar conciencia de su trascendente personalidad, de su rol fundamental en la sociedad, la cultura y la época que le ha tocado vivir, y de su responsabilidad con todo lo circundante, pues es un ser en relación. Tanto el diseño de los planes curriculares como el de las estratégicas metodológicas y su ejecución deben estar fundamentados en lo que define nuestra condición humana, nuestra capacidad de maravillarnos, de sorprendernos, de contemplar, de ir en busca de aquello que apreciamos como el mayor bien y verdad, posibles. 
El término "éxtasis", de origen griego, consta del prefijo [ek], con el valor semántico de 'salida de', y el sustantivo [stásis], cuyo significado es el de "estado de conciencia, estado de ser, estado de mentalidad". La palabra tiene, entonces, el sentido de salida de un estado de ser para entrar en otro estado de ser que incluye, a su vez, la salida de un estado de conciencia inferior para entrar en otro estado de conciencia superior. Es decir, la energía extática capacita al ser humano para superar el solipsismo de su "yo" y unirse a todo aquello que, transcendiendo este "yo", le motiva a elevarse sobre sí mismo (Rielo, 2001b, p. 138).

La educación en el éxtasis implica tener en cuenta lo más importante para la persona humana: su vocación transcendente, su ansia de horizontes amplios e ilimitados, su condición comunicativa e integradora, sin la cual ninguna propuesta pedagógica puede estar completa.

Silenciar intencionalmente esta trascendencia del ser humano en el ámbito educativo es introducir la mala fe en el ejercicio pedagógico. Uno de los males de la pedagogía es que no ha definido al ser humano en su dimensión extática, sino que se ha limitado a describir fenómenos educativos: fenomenología que nos ha llevado a la más abyecta dispersión (López, 1985, p. 32).

La experiencia pedagógica debe pasar de saber hacer cosas a saber sobre el propio ser, a generar espacios para ser personas, a través de mantener alerta la natural capacidad inquisitiva, contemplativa y extática de los estudiantes y así convertir al proceso de enseñanza-aprendizaje en una experiencia de empatía, de compromiso, de comprensión y restauración, que solamente es posible con una actitud de apertura, de salida, de encuentro con todo lo circundante. La experiencia extática es la forma como elevamos nuestro espíritu sobre la mediocridad, la indiferencia, la negligencia en todo acto pedagógico. "El profesor ha de fomentar las pasiones intelectuales, porque son lo contrario de la apatía esterilizadora que se refugia en la rutina y que es lo más opuesto que existe a la cultura" (Cifuentes, 2014, p. 106). 
Lamentablemente, en la actualidad se promueve que el maestro ha de ser neutral y no tomar partido de ninguna índole, la apología que se ha hecho de la libertad de expresión, tendencia, culto, ideología, mal entendida e interpretada, nos está llevando al libertinaje deshumanizado de una sociedad confundida y sin horizontes (Cifuentes, 2014, p. 108). El maestro, como hace Don Quijote con Sancho Panza debe entusiasmar a su discípulo por la empresa vital en que se aventura, solo entonces se vislumbra horizontes y se abren senderos. Si el maestro no contagia la pasión por lo que enseña, si no hay una simetría entre lo que se cree y se proyecta, no se podrá despertar la ilusión por el conocimiento, ni potenciar al alumno hacia los mayores logros.

Frente a las muestras de autenticidad con que Don Quijote asume su rol de caballero llevado a cabo con extremo cuidado, esmero, dedicación, hasta alcanzar la perfección, Sancho afirma: "Yo me he arrimado a buen señor, y ha muchos meses que ando en su compañía, y he de ser otro como él, Dios queriendo; y viva él y viva yo, que ni a él le faltarán imperios que mandar, ni a mí ínsulas que gobernar" (Cervantes, 2004, p. 794). Esta experiencia pedagógica une a discípulo y maestro en una misma pasión por la vida, por buscar la mejor manera de llevar adelante la empresa en la que cada uno está comprometido.

“¿No parte la educación del supuesto de que el ser humano es perfectible? Son muchos los autores que afirman que la realidad de la perfección activa en el hombre su progreso educativo" (López, 1985, p. 17). La experiencia pedagógica debería conducir al estudiante a la superación de sí mismo, a la restauración de aquellos aspectos que han deteriorado su manera de mirar, de situarse en el mundo, de valorar. Debería permitir que pueda elevarse de posiciones autorreferenciales, libre de condicionamientos, de prejuicios que nublan la recepción crítica de todo lo que le rodea. Una propuesta pedagógica debería permitir al estudiante vincular el conocimiento de algo nuevo con su historia, su cultura, su experiencia personal, y potenciar su creatividad para aplicar las nuevas nociones a realidades prácticas. Cuando se convierte al acto pedagógico 
en una experiencia vital que eleva al estudiante de su estado inicial, que lo restaura y lo engrandece, el maestro puede apreciar el crecimiento de sus estudiantes, el desarrollo de su curiosidad intelectual, de su autonomía inquisitiva, de su responsabilidad con su aprendizaje y con su entorno.

\section{La necesaria formación humanística}

La educación entendida como la potenciación de la condición humana nos debe llevar a un continuo proceso de superación de las propias limitaciones y a una compenetración responsable, solidaria y auténtica con el entorno social e intelectual en el que educadores y educandos se desenvuelven. Esta perfectibilidad fundamentada en la educación extática hunde sus raíces en el "saber humanístico, saber que gira en torno a la persona humana: su conducta, sus creencias, su expresión individual, su existencia" (Contreras, 1999, pp. 4-5). Frente a la tendencia de hoy en día de pensar la educación como sinónimo de adquisición del conocimiento, las humanidades nos recuerdan que su "misión ... es ayudar a construir y trasmitir más entendimiento y comprensión que conocimientos" (Contreras, 1999, p. 5).

Las asignaturas que comportan las humanidades están dirigidas a "la maduración de la persona como ser humano, [...] está[n] interesada[s] en preservar y desarrollar las artes y habilidades que encuentran su expresión en los grandes objetivos, problemas y valores del interés humano" (Cifuentes, 2014, p. 105). Las humanidades ofrecen el contexto preciso para que los estudiantes puedan llegar a: "discutir, pensar, razonar, a no conformarse, a llegar a convicciones más profundas de la vida y su dignidad como seres humanos y su papel en la sociedad, sin olvidar la esencia del ser en sí mismo" (Cifuentes, 2014, p. 110).

Fernando Rielo señala que "El joven es más ilusión que pensamiento, por eso necesita, más que amigos, un maestro" (2002, p. 25); personas que estén dispuestas a motivar su naturaleza inquisitiva, a ayudarle a conocerse, a proponer retos y luchar por alcanzarlos, a dar unidad, 
dirección y sentido a su existencia, con "“sensibilidad y disciplina', para embarcarse en la búsqueda y exploración de la condición humana, en la indagación que le permita saber quién es, de dónde viene, cuál es su historia y hacia dónde va, en fin cuál es su esencia y existencia como humano" (Cifuentes, 2014, p. 110).

La formación de los estudiantes en el ámbito universitario y su preparación para el futuro ejercicio de una profesión requiere, por tanto, no solo de los saberes

técnicos y propios de la disciplina [sino también] de los humanísticos pertinentes a la esencia del mismo ser; pues [no solo] se requiere de personas idóneas en su área [sino] ante todo de personas humanas, empáticas, que sientan lo que sienten sus congéneres, con proyección, con criterio y libertad de acción, dispuestas a restaurar una sociedad sumergida en medio de un caos de deshumanización (Cifuentes, 2014, p. 104).

Siguiendo a Fernando Vázquez Rodríguez (2016), podríamos afirmar que las humanidades flexibilizan al espíritu y dan un carácter plástico al pensamiento, presentan un horizonte más amplio de los problemas esenciales del ser humano, evitando la exagerada compartimentación del conocimiento, nos vuelven empáticos e incluyentes, y ayudan a desarrollar el pensamiento crítico y las habilidades argumentativas.

Las humanidades constituyen el eje fundamental en la formación de los estudiantes, ya que, por un lado, puede combinar "instrucción y educación; aptitud y actitud; competencia y formación, autenticidad y responsabilidad" (Lacilla, 2018, p. 214), y por otro, bien conducidas, generan el espacio que permite abrir la tarea pedagógica hacia experiencias que promuevan "confianza, buena voluntad y sensibilidad frente a los valores trascendentes que nos definen como personas" (Lacilla, 2018, p. 216). 


\section{A manera de conclusión}

En tiempos en los que las humanidades están siendo desplazadas o desvaloradas, es urgente recordar que no hay tarea educativa sin la transformación, elevación y proyección del estudiante hacia lo que aprecia como valioso, verdadero y auténtico. El ámbito de las humanidades proporciona el espacio para un crecimiento progresivo dentro de un proceso que involucra al educando con preguntas trascendentales, con habilidades y destrezas cognitivas y reflexivas, con los valores, historia, sociedad y cultura que lo constituyen.

Esta experiencia debe estar fundada en la educación de la energía extática, esencial al espíritu humano. La educación debe potenciar la capacidad de sorprenderse. La tarea del docente es acompañar al educando a extasiarse "ante las cosas, los acontecimientos, los principios y fundamentos, pero el maestro solo podrá enseñar con eficacia en la misma medida que él sea verdadero discípulo" (Giménez \& Gómez, 2005, p. 77). Involucrarse en una tarea pedagógica implica que el maestro desarrolle su propia energía extática y proyecte lo mejor de sí mismo, como requisito indispensable para no traicionar la autenticidad en el proceso de enseñanza-aprendizaje. Quien ha hecho del ejercicio educativo una experiencia de superación constante podrá impulsar el desarrollo de sus educandos, quien ha mirado más allá de lo evidente, sabrá identificar otras maneras de mirar en los ojos de sus alumnos, y así evitar la superficialidad y la instrumentalización del conocimiento y de las personas.

La potenciación de la condición humana es posible cuando pasamos, del saber acerca de las cosas, y del domino y manejo de las mismas, al saber acerca del propio ser y del modo cómo afrontar la vida. Entonces, se puede dar dirección y sentido a nuestra historia, establecer los vectores que permitan encontrar la finalidad, convicción, decisión y compromiso de nuestra existencia. Las humanidades aportar el contexto en el cual se puede dar el crecimiento de todo estudiante universitario y se constituyen en una "herramienta para el profesional íntegro comprometido con una 
sociedad donde pueda actuar con espíritu crítico, analítico, argumentativo y propositivo y aportar a su transformación y restauración de la dignidad del ser humano" (Cifuentes, 2014, p. 105).

Cuando se impulsa la capacidad extática de los estudiantes, la experiencia pedagógica se convierte en una vivencia crítica y creativa, que permite al educando sentir que puede aportar, que es capaz de analizar, valorar, evaluar, proponer, construir, proyectar la mejor versión de sí mismo, engrandeciendo el contexto en el que crece y actúa. 


\section{Referencias bibliográficas}

Blecua, J. M. (1999). La enseñanza de las humanidades. Madrid: Santillana.

Bullock, A. (1989). La tradición humanista en Occidente. Madrid: Alianza.

Cervantes, M. (2004). El ingenioso hidalgo Don Quijote de la Mancha. Madrid: Santillana.

Cifuentes Medina, J. E. (2014). El papel de las humanidades en la educación superior en el siglo XXI. Revista Quaestiones Disputatae. Temas de debate, 15, 101-112.

Contreras, C. A. (1999) Concepto de las humanidades. Disponible en https://studylib.es/ doc/270354/concepto-de-lashumanidades---un-virtual

Cordua, C. (2012). La crisis de las humanidades. Revista de Filosofía, 68, 7-9. Disponible en http://dx.doi.org/10.4067/S071843602012000100002

Cots, V. M. (2006). Crisis de las humanidades, crisis del canon. Mil Seiscientos Dieciséis. Anuario, 11, 253-260.

Culler, J. (1988). El futuro de las humanidades. En El canon literario (139-160). Madrid: Arco / Libros.

Díaz Villarreal, W. (2015). Las humanidades, la universidad y la era de la excelencia académica. Literatura: Teoría, Historia, Crítica. 17(2), 19-38. Disponible en http://dx.doi.org/10.15446/lthc. v17n2.51270.

Grassi, E. (1999). La filosofía del Humanismo. Preeminencia de la palabra. Barcelona: Anthropos.

Guerra, Y. M. (2008) ¿Las humanidades en crisis o la crisis de la humanidad? Revista Educación y desarrollo social, 2(2), 135-142. Disponible en https://doi.org/ 10.18359/reds.828 
Giménez A. \& Gómez, M. I. (2005). Pedagogos cristianos. Loja: UTPL. Ibáñez-Martín, J. A. (1995). Hacia una formación humanística. Objetivos de la educación en la sociedad cientifico-técnica. Barcelona: Herder.

Jocelyn, H. D. (1973) Homo sum: humani nil a me alienum puto (Terence, Heauton timorumenos 77) Antichthon 7, 14-46.

Lacilla, M. F. (2018). La libertad y su educación desde la perspectiva de Fernando Rielo. En Proceedings Sixth World Conference on Metaphysics (209-220). Madrid: Fundación Fernando Rielo.

López, J.M. (1985). El Modelo pedagógico. Boletín Idente. 12

Mollis, M. (Comp.) (2003). Las universidades en América Latina: ¿reformadas o alteradas? La cosmética del poder financiero. Buenos Aires: CLACSO.

Nussbaum, M. (2005). El cultivo de la humanidad: una defensa clásica de la reforma en la educación liberal. Juana Pailaya, (trad.). Barcelona: Paidós.

Rielo, F. (2001a). Filosofía sicoética. En Mis meditaciones desde el modelo genético (121-142). Madrid: Fundación Fernando Rielo.

Rielo, F. (2001b). Función de la fe en la educación para la paz. En Educar desde y para la paz (97-119). Madrid: Fundación Fernando Rielo.

Rielo, F. (2002). Transfiguración. (2da ed.). Madrid: Fundación Fernando Rielo.

Savater, F. (1997). El valor de educar. Barcelona: Editorial Ariel Urrea. 